\title{
Brain MRI Findings in Infantile Spasm: Outcome Correlations in a Patient Cohort
}

\author{
Alireza Khatami ${ }^{*}$, Erick Sell², Mohamed Aggag1, Elka Miller ${ }^{1}$ \\ ${ }^{1}$ Department of Medical Imaging, Children's Hospital of Eastern Ontario, University of Ottawa, Ontario, Canada \\ ${ }^{2}$ Department of Pediatrics, Division of Neurology, Children's Hospital of Eastern Ontario, University of Ottawa, Ontario, Canada \\ Email: *alireza_khatami31@yahoo.com
}

How to cite this paper: Khatami, A., Sell, E., Aggag, M. and Miller, E. (2016) Brain MRI Findings in Infantile Spasm: Outcome Correlations in a Patient Cohort. Open Journal of Medical Imaging, 6, 80-92. http://dx.doi.org/10.4236/ojmi.2016.63008

Received: July 25, 2016

Accepted: September 9, 2016

Published: September 12, 2016

Copyright $\odot 2016$ by authors and Scientific Research Publishing Inc. This work is licensed under the Creative Commons Attribution International License (CC BY 4.0).

http://creativecommons.org/licenses/by/4.0/

(c) (i) Open Access

\begin{abstract}
Background: Infantile spasm is a type of pediatric seizure often associated with a negative prognosis. The aim of this study was to evaluate the role of Magnetic Resonance Imaging (MRI) in categorization and neurodevelopmental outcomes in children with infantile spasm. Materials and Methods: A retrospective study of the clinical charts and MRI findings of infants diagnosed with infantile spasm between December 2007 and February 2014. Results: A total of 26 children (16 males; 1.6/1) were included: 8 of unknown etiology and 18 with a genetic/structural-metabolic causes. Unknown etiology cases revealed normal brain MRI in 5/8 (62.5\%). In the genetic/ structural-metabolic group, only $2 / 18$ (11.1\%) had normal imaging. Abnormal imaging findings significantly correlated with genetic/structural-metabolic infantile spasm which had unfavorable neurodevelopmental outcome. Conclusion: Neuroimaging conveys substantial information to the further categorization of children with infantile spasm, providing not only relevant information of the underlying cause but also the prediction of the neurodevelopmental outcome.
\end{abstract}

\section{Keywords}

Infantile Spasm, Magnetic Resonance Imaging, Brain Imaging, Infant, Vigabatrin

\section{Introduction}

Infantile spasm is a specific type of seizure that is seen in infancy and childhood [1] with an incidence rate of $2-5$ cases per 10,000 live births [2]-[5]. It is defined as an abrupt, often clustered, extension-flexion or mixed extension-flexion movement of primarily the proximal and truncal muscles [6]. West syndrome is an epileptic syndrome which presents with infantile spasms. The criteria to diagnose West syndrome includes: i) developmental plateau or regression [7] [8]; ii) seizure type (epileptic spasm) 
and iii) hypsarrhythmia pattern on electroencephalography (EEG) [9]. The great majority of patients with infantile spasms will also have developmental problems and hypsarrhythmia on EEG, and therefore patients with West syndrome or just infantile spasms tend to be reported as one group [10] [11]. This is the group in our study.

The prognosis of infantile spasm is multifactorial and depends on: i) the underlying cause, i.e. congenital brain malformation; ii) the pattern of electroencephalography; iii) the appearance of seizures prior to the spasms; and iv) a rapid response to treatment [12].

Current classification of infantile spasm refers to genetic, structural-metabolic, and unknown cause [13], replacing the previous use of idiopathic, symptomatic, and cryptogenic respectively. Etiologic classification of infantile spasm has shown structuralmetabolic abnormalities in $68 \%$ of children, unknown etiology in $24 \%$ of children and genetic causes in $8 \%$ of children [14]. MRI can provide information regarding etiology, thus can aid in the categorization of infantile spasm [15].

The purpose of this study was to compare MRI findings with neurodevelopmental outcomes in children with infantile spasm where preliminary clinical work up did not lead to a specific etiological diagnosis.

\section{Materials and Methods}

\subsection{Subjects}

This retrospective review included the clinical charts of 26 infants with infantile spasm that underwent brain MRI and clinical follow-up between December 2007 and February 2014. These cases were extracted from the hospital medical records of 400 children with seizures admitted during that period. Inclusion criteria included; a) infants with clinical evidence of infantile spasm; b) proven by hypsarrhythmia or modified hypsarrhythmia on electroencephalogram EEG after neonatal period to 12 months of age. Children were excluded if: a) other types of seizures were encountered, b) if clinical and EEG findings were not supportive of infantile spasm, or c) if images were of poor quality. Prior to evaluation of the MRI findings, the cases were classified as structural-metabolic, genetic, or infantile spasm of unknown etiology based on clinical information, EEG and laboratory tests.

\subsection{MRI Technique and Interpretation}

All children underwent an MRI scan on a 1.5 Tesla clinical MR system (Signa HD, General Electric Healthcare Technologies, Waukesha, WI, USA). All children were given anesthesia which was administered by a pediatric anesthesiologist as per departmental protocol. Images were acquired using an 8-channel head coil. All of the MRI's included the following sequences (time of repetition/time of echo/thickness/field of view): Axial T1 Fluid-Attenuation Inversion Recovery $(9502 / 125 / 5 / 352 \times 224)$, axial T2 Fast Spin Echo $($ FSE) $(2221 / 26 / 5 / 320 \times 256)$, coronal T2 FSE $(5000 / 101 / 5 / 320 \times 256)$, fast relaxation fast spin echo $(\mathrm{frFSE})(4650 / 102 / 5 / 320 \times 256)$, sagittal T1 Fluid-Attenuation Inversion Recovery $(2100 / 24 / 5 / 320 \times 256)$, Diffusion Weighted Images $(D W I)(8000 / 72 / 5 / 128 \times$ 
128), and coronal Fast Spoiled Gradient-Recalled brain volume imaging (FSPGR BRAVO) (Flip angle 14/TI10.4/thickness1.2/320 × 320). Susceptibility weighted angiography imaging (SWAN) (78.3/50/10/288/224) was done on patients who were imaged in 2010 and thereafter.

\subsection{Data Collection}

Medical records were systematically reviewed. Data regarding gestational age at birth, the age at first spasm, course of the disease, treatment history, time under follow-up and the outcome of the patient was reviewed. MR images were reviewed by a pediatric radiology fellow (AK) who was blinded to the underlying diseases, clinical history and outcome. Image findings were compared to the clinical report in the Picture Archiving and Communication System PACS. The median follow-up period for infantile spasm patients was 29 months (range 1 - 66.7 months).

The diagnosis of infantile spasm and the EEG findings were confirmed by a pediatric neurologist with 7 years of experience in pediatric neurology (ES).

All patients received therapeutic regimen including Vigabatrin and/or adrenocorticotrophic hormone ACTH.

The initial classification of infantile spasm was correlated to the MRI findings and final diagnosis, as documented in clinical follow-up records, to evaluate the usefulness of MRI in the categorization of infantile spasm. Finally, the neurodevelopmental outcome was evaluated according to response to treatment for spasms and seizure control and the presence of any degree of developmental delay/regression for each group.

Children with no or mild developmental delay, without spasm or other seizure activities were categorized as favorable neurodevelopmental outcome while children with moderate-severe developmental delay and with other seizure activities and/or spasm were categorized as unfavourable neurodevelopmental outcome. The degree of developmental delay (mild, moderate, severe) was extracted from the chart information as per clinicians' decision. Data was analyzed using a two tailed Fisher exact test for any correlations and the p-values were calculated.

\section{Results}

The age of initial infantile spasm onset ranged between 2 - 11.5 months (mean 6.4 months). The mean onset age was 6.6 months (5 - 9 months) for infantile spasm of unknown etiology, and 6 months (2 - 11.5 months) for genetic/structural-metabolic infantile spasm. Clinical follow-up time ranged between 1 - 66.7 months (mean 29 months). Demographics are summarized in Table 1.

\subsection{Value of Neuroimaging for the Clinical Diagnosis}

MRI was supportive in the classification of $14 / 26$ children with infantile spasm, changing the diagnosis in $8 / 16$ children with infantile spasm of unknown etiology to structural-metabolic group ( $\mathrm{p}$-value $=0.0256$ ).

Based on clinical information, EEG, and laboratory tests, 10/26 (38.46\%) structural- 
metabolic or genetic group (including sequelae of hypoxic-ischemic encephalopathy and meningitis) were diagnosed prior to imaging. In 6/10 (60\%) cases, MRI revealed abnormalities in support of the diagnosis and in the other $4 / 10$ (40\%) cases, MRI did not add additional information ( 2 had non-specific MRI changes and 2 had a normal MRI; 3/4 of these cases had chromosomal abnormalities).

Unlike the above group, MRI was helpful in the further classification of the remaining 16/26 (61.54\%) children with infantile spasm who had no identifiable cause, changing the diagnosis in $8 / 16$ children with clinically unknown infantile spasm to structuralmetabolic while the remaining $8 / 16$ children stayed as unknown group ( $\mathrm{p}$-value $=$ $0.02)$.

Final classification of this cohort resulted in 18/26 (69.23\%) children with genetic/structural-metabolic infantile spasm and 8/26 (30.77\%) with unknown etiology infantile spasm based on combination of clinical, laboratory and neuroimaging findings (Diagrams 1 (a)-(c), Figure 1 and Figure 2).

Table 1. Demographics of infantile spasm cases in either category; gestational age, age at first spasm, duration of follow-up and neurodevelopmental outcome.

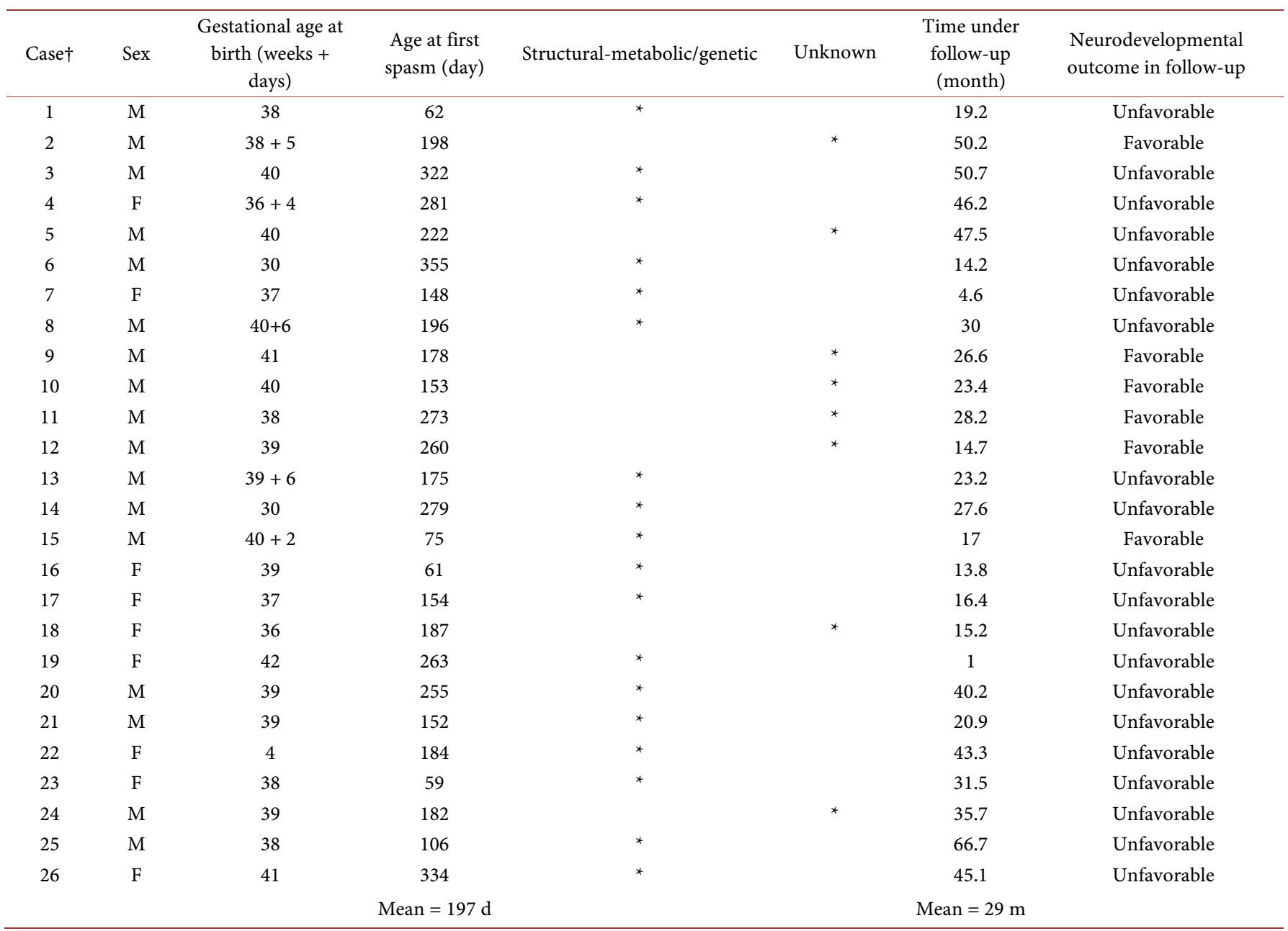

†Case no. 19 died one month after starting treatment due to Leigh disease. $\mathrm{M}=$ male; $\mathrm{F}=$ female; $\mathrm{m}=\mathrm{month} ; \mathrm{d}=$ day. 
1(a): Infantile spasms with known etiologies based on clinical findings in 26 cases.

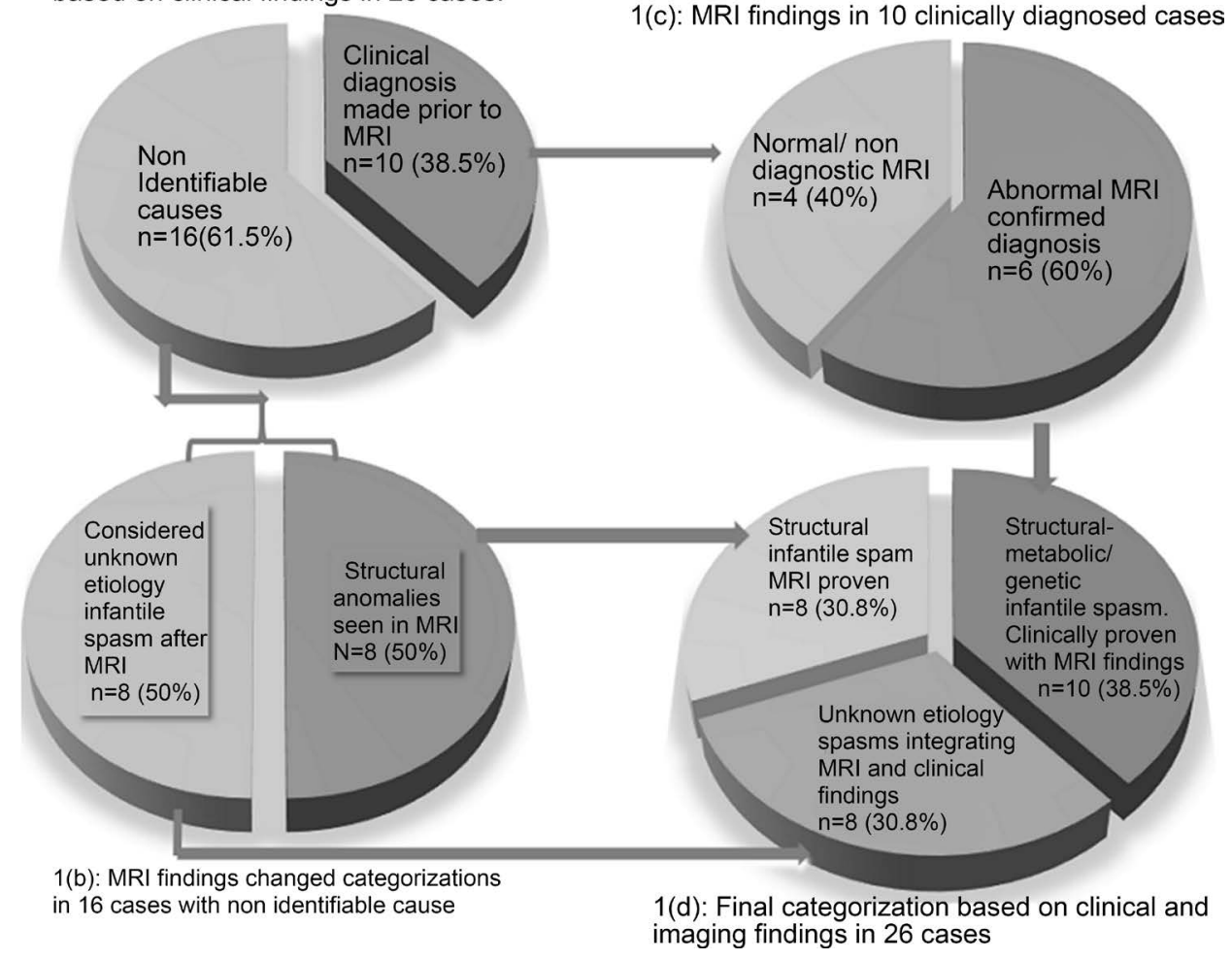

Diagram 1. Infantile spasm categorization: (a) based on clinical diagnosis; (b) \& (c) integrating MRI findings for further categorization; (d) final categories of infantile spasm in the cohort.

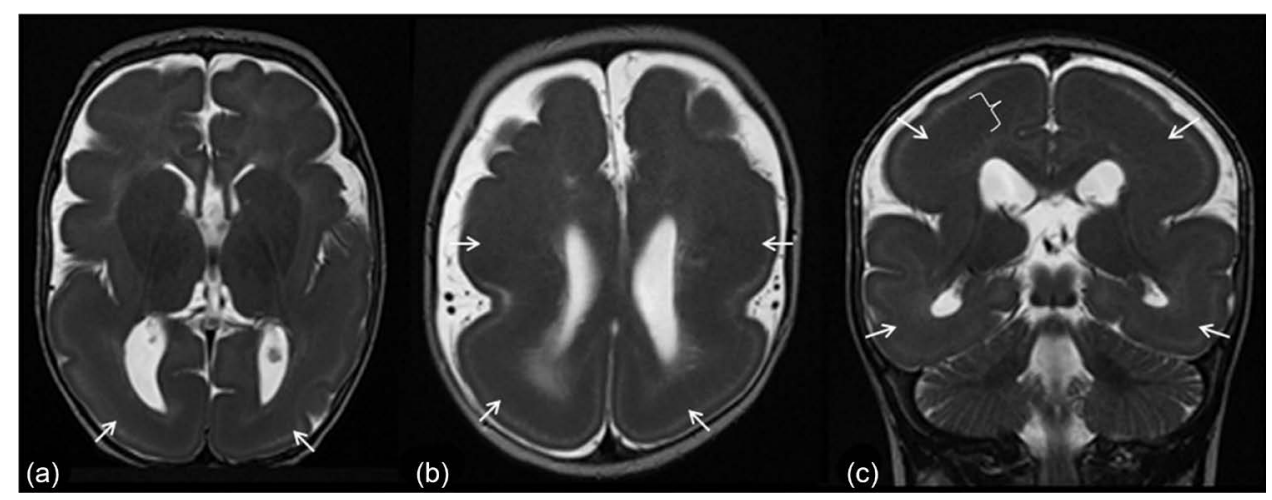

Figure 1. A 6-month-old baby boy with Miller-Dieker syndrome (case no. 13). No definitive etiology before imaging. Axial (a, b) and coronal (c). T2 weighted images demonstrate lissencephaly agyria/pachygyria and thickened, band-like heterotopia in subcortical white matter known as double-cortex (arrows). The thickness of the band heterotopia is marked with a brace in the image (c). The image findings assisted in coming to a final diagnosis for this child.

\subsection{Imaging Findings of Infantile Spasm}

The etiologic causes in the structural-metabolic or genetic group are summarized in Table 2. In $3 / 8$ (37.5\%) cases of infantile spasm of unknown etiology, nonspecific and minor imaging abnormalities were demonstrated (Table 3, cases 3, 4 and 7). On the contrary, among the 18 cases of structural-metabolic or genetic infantile spasm, 16/18 


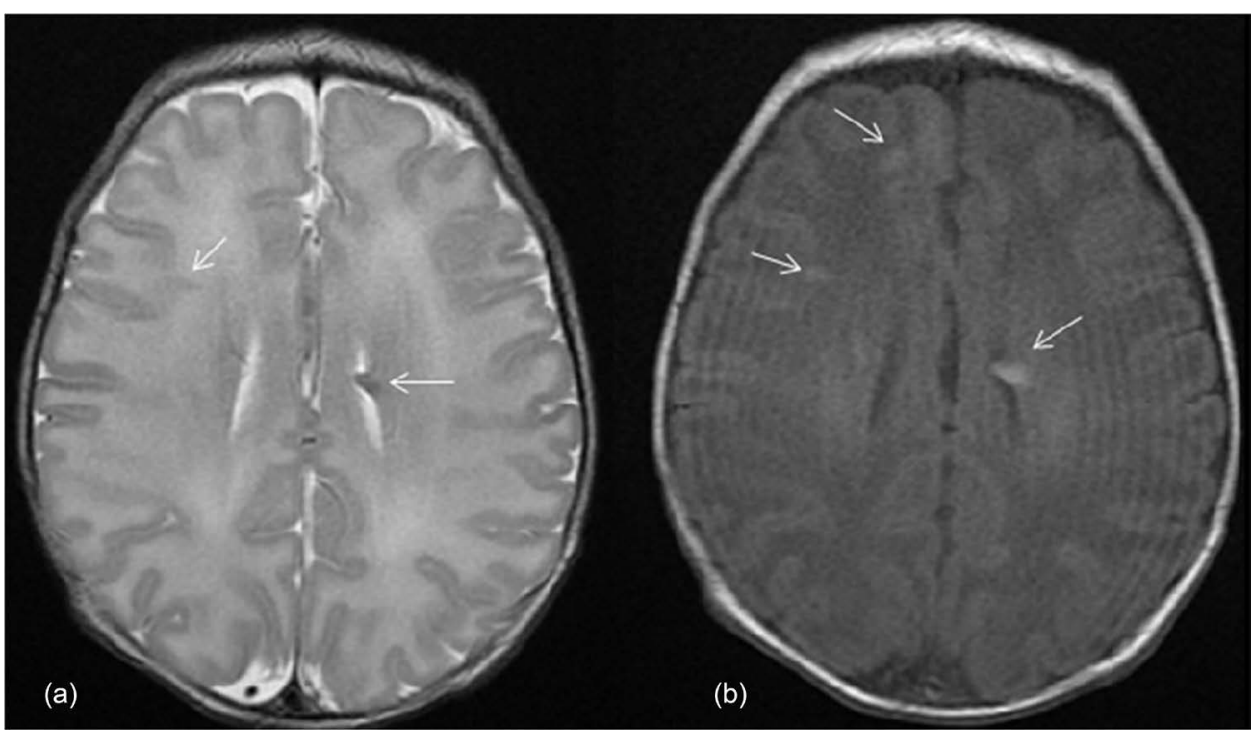

Figure 2. 2-month-old term baby girl (case no. 23) with spasms and without identifiable etiology prior to imaging. Axial T2W image (a) demonstrated foci of hypointensities on the frontal subcortical and periventricular white matter (arrows). T1W image (b) revealed hyperintensities on the same regions visualized on T2W images (arrows) due to subcortical and sub ependymal tubers of tuberous sclerosis. The patient categorization changed to structural type infantile spasm.

Table 2. Etiologic causes of structural metabolic/genetic infantile spasm.

\begin{tabular}{cc}
\hline Etiologies & No. (percent) \\
\hline Muberous sclerosis (includes one with hemimegalencephaly) & $3(16.66)$ \\
Lissencephaly with heterotopia and polymicrogyria & $3(16.66)$ \\
Hypoxic-ischemic encephalopathy (HIE) sequela & $3(16.66)$ \\
(one case had Williams syndrome) & $2(11.11)$ \\
Trisomy 21 & $2(11.11)$ \\
Trisomy 15 & $1(5.56)$ \\
Meningitis with infarct & $1(5.56)$ \\
Frontal heterotopia & $1(5.56)$ \\
Congenital hypothyroidism & $1(5.56)$ \\
Septo-optic dysplasia & $1(5.56)$ \\
\hline
\end{tabular}

Table 3. MRI findings in infantile spasm of unknown etiology.

\begin{tabular}{|c|c|c|c|c|c|}
\hline Case\# & $\mathrm{N}$ & Thin CC & Widened CSF & Mild VM & Other \\
\hline 1 & * & & & & \\
\hline 2 & * & & & & \\
\hline 3 & & & * & * & \\
\hline 4 & & * & * & & \\
\hline 5 & * & & & & Pineal cyst $8 \mathrm{~mm}$ \\
\hline 6 & * & & & & Rvisc \\
\hline 7 & & & & & $\mathrm{Ba}$ \\
\hline 8 & * & & & & \\
\hline
\end{tabular}

$\mathrm{N}$ = normal; $\mathrm{CC}=$ corpus callosum; $\mathrm{CSF}$ = cerebrospinal fluid; $\mathrm{VM}=$ ventriculomegaly; Rvisc = reversible vigabatrin-induced signal changes; $\mathrm{Ba}=$ blooming artifacts. \#Case 7 demonstrated a small cavernoma in the posterior fossa, unlikely related to infantile spasm. 
(88.9\%) demonstrated MRI abnormalities and only 2/18 (11.1\%) children had normal neuroimaging. The correlation between abnormal MRI and structural-metabolic or genetic type infantile spasm was significant ( $\mathrm{p}$-value $=0.01$ ). A summary of neuroimaging findings in structural-metabolic or genetic infantile spasm are found in Table 4.

\subsection{Follow-Up \& Outcome}

Clinical follow-up ranged between 1 - 66.7 months (mean 29 months). In 17/26 (65.38\%) cases, there was no spasm present in the follow-up, but other seizure activities continued in 15/26 (57.7\%) cases, of which 5 (19.23\%) cases had refractory seizures.

Spectrum of developmental delay was observed in $24 / 25$ (96\%) children. One child with Leigh disease deceased one month after initiation of antiepileptic therapy.

Table 4. MRI findings in structural-metabolic/genetic infantile spasm.

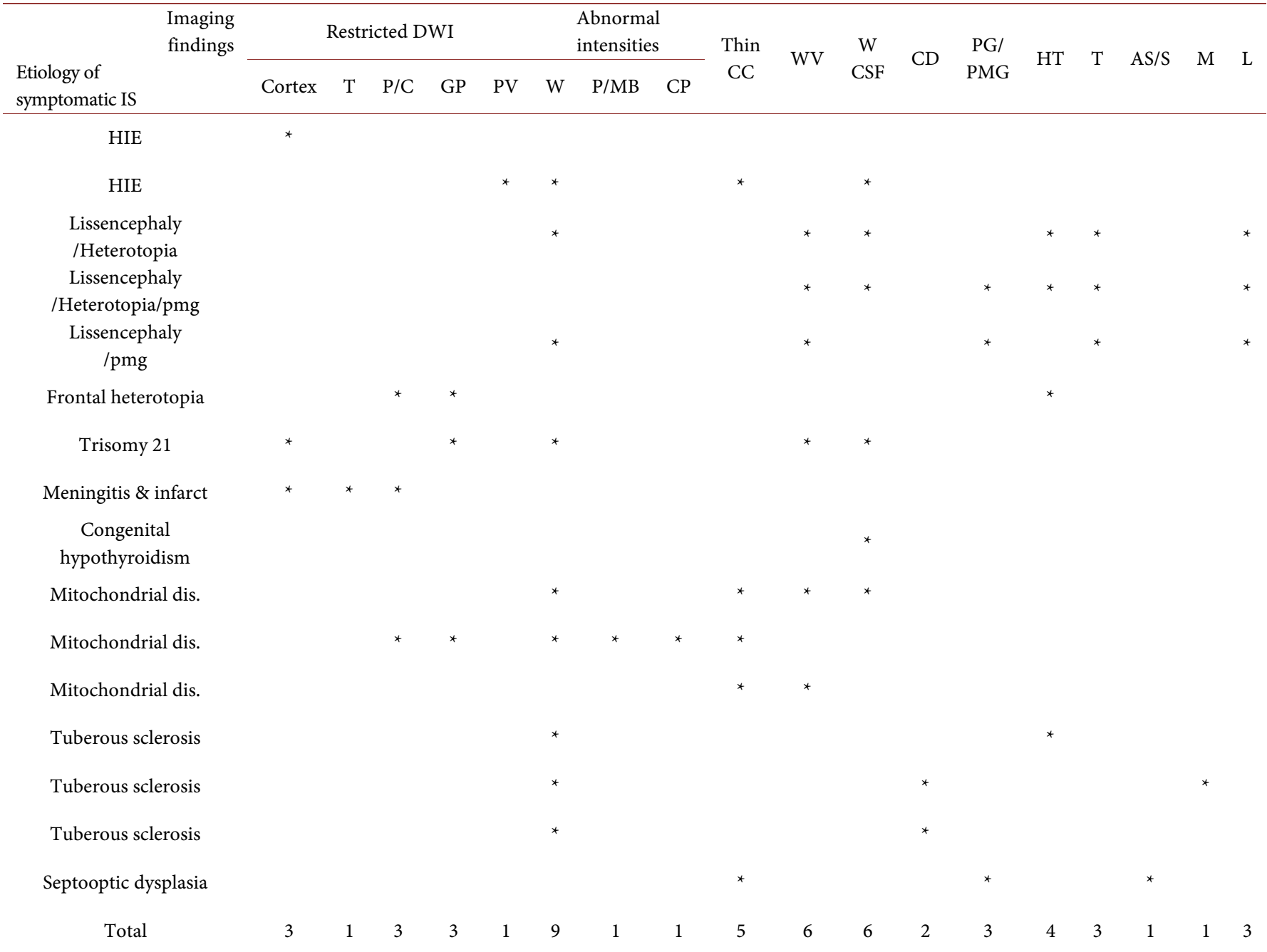

$\dagger \mathrm{IS}=$ infantile spam; $\mathrm{HIE}=$ hypoxic-ischemic encephalopathy; $\mathrm{T}=$ thalamus; $\mathrm{P} / \mathrm{C}=$ putamen/caudate; $\mathrm{GP}=$ globus pallidus; $\mathrm{PV}=$ periventricular white matter; $\mathrm{W}=$ white matter; $\mathrm{P} / \mathrm{MB}=$ pons/midbrain; $\mathrm{CP}=$ cerebral peduncles; $\mathrm{CC}=$ corpus callosum; $\mathrm{WV}=$ widened ventricle; $\mathrm{WCSF}=$ widening of $\mathrm{CSF}$ space; $\mathrm{CD}=$ cortical dysplasia; PG-PMG/pmg = pachygyria-polymicrogyria; $\mathrm{HT}=$ heterotopia; $\mathrm{T}=$ tuber; $\mathrm{AS} / \mathrm{S}=$ absent septum pellucidum/schizencephaly; $\mathrm{M}=$ megalencephaly; $\mathrm{L}=$ lissencephaly; dis = disease. $\dagger \dagger 2$ cases with trisomies 21 and 15 had normal imaging. They are not included in the table. $\dagger \dagger \dagger$ Case with trisomy 15 revealed rvisc "reversible vigabatrin-induced signal changes" and not shown in this table. 
Among infantile spasm of unknown etiology, complete resolution of spasm was achieved in 7/8 (87.5\%) cases; but 3 of them continued to have other seizure types (one refractory, one focal motor and one complex partial seizure). This group of infantile spasm encountered a spectrum of delay in developmental milestone achievements in $7 / 8$ (87.5\%) cases; 3 with mild delay. Only $1 / 8$ (12.5\%) case with infantile spasm of unknown etiology achieved a normal developmental milestone at 26.6 months follow-up with complete resolution of spasm and no seizure activities on anticonvulsant (Table $5)$.

In contrary, among the structural-metabolic and genetic infantile spasm cases, there was heterogeneity in resolution of spasm and other seizure activities. As shown in Table 5 and Table 6, spasm resolution irrespective of having other types of seizures, was observed in 10/18 (55.55\%) children while seizures with/without spasm continued in $12 / 18$ (66.67\%) children; 4 of whom had refractory seizures. Only 2/18 (11.1\%) children categorized as structural-metabolic and genetic infantile spasm became spasm and seizure free in follow-up.

The difference of spasm resolution between the infantile spasm of unknown etiology and structural-metabolic/genetic group was not statistically significant ( $\mathrm{p}$-value $=0.19$ ). All children with structural-metabolic and genetic infantile spasm demonstrated developmental delay including regression in 2 patients (Table 6).

Among the group of infantile spasm with unknown etiology, 5/8 (62.5\%) cases had favorable neurodevelopmental outcome regarding spasm resolution, discontinued seizure activity and mild or no developmental delay while only $1 / 18$ children in the structural-metabolic or genetic cases had favorable outcome (Diagrams 2 (a)-(c)). The difference was significant ( $\mathrm{p}$-value $=0.004)$.

Table 5. Outcome of infantile spasm of unknown etiology.

\begin{tabular}{|c|c|c|c|c|}
\hline Case no & Spasm & Seizure & Developmental delay & Favorable outcome \\
\hline 1 & & & ${ }^{*} \mathrm{M}$ & + \\
\hline 2 & * & * & ${ }^{*} \mathrm{~A}$ & \\
\hline 3 & & & & + \\
\hline 4 & & & * & + \\
\hline 5 & & & * & + \\
\hline 6 & & & ${ }^{\star} \mathrm{M}$ & + \\
\hline 7 & & ${ }^{*} \mathrm{R}$ & * & \\
\hline$\dagger 8$ & & ${ }^{*} \mathrm{~F}$ & ${ }^{\star} \mathrm{M}$ & \\
\hline
\end{tabular}

If patient had spasm, seizure or developmental delay, it is marked as *. Patient with favorable neurodevelopmental outcome marked as $+\mathrm{M}=$ minimal. $\mathrm{R}=$ refractory. $\mathrm{F}=$ focal. $\mathrm{A}=$ autism. $\dagger$ Based on our criteria, continued any type of seizure and/or spasm with any degree of developmental delay considered as unfavourable outcome. 
Table 6. Outcomes of structural-metabolic/genetic infantile spasm.

\begin{tabular}{|c|c|c|c|c|}
\hline Etiologies & Spasm & Seizure & Developmental delay & Favorable outcome \\
\hline HIE & & ${ }^{*} \mathrm{R}$ & * & \\
\hline Meningitis \& infarct & * & ${ }^{*} \mathrm{R}$ & * & \\
\hline Mitochondrial & * & * & * & \\
\hline HIE & * & & * & \\
\hline Lissencephaly & * & & * & \\
\hline Septooptic dys. & * & & * & \\
\hline Lissencephaly, Milker-Dieker syn. & & * & * & \\
\hline Trisomy 21 & ${ }^{*} \mathrm{R}$ & * & * & \\
\hline Tuberous sclerosis & & & $\dagger^{*}$ & * \\
\hline Lissencephaly & & * & * & \\
\hline Frontal heterotopia & & * & * & \\
\hline Leigh disease & * & * & $\mathrm{N}$ & \\
\hline Con. hypothyroidism & & * & * & \\
\hline Trisomy 21 & ${ }^{\star} \mathrm{R}$ & & ${ }^{\star} \operatorname{Reg}$ & \\
\hline Tuberous sclerosis & & * & * & \\
\hline Tuberous sclerosis & & ${ }^{*} \mathrm{R}$ & * & \\
\hline Mitochondrial & & ${ }^{*} \mathrm{R}$ & * & \\
\hline Trisomy 15 & & & ${ }^{\star} \operatorname{Reg}$ & \\
\hline
\end{tabular}

If patient had spasm, seizure, developmental delay or favorable neurodevelopmental outcome, it is marked as *. HIE = hypoxic-ischemic encephalopathy; dys = dysplasia; $c 0 n=$ congenital; $\mathrm{N}=$ not applicable (Patient deceased). Reg = regression; $\mathrm{R}=$ refractory; syn $=$ syndrome $\dagger=$ this patient had mild delay.

\subsection{Treatment Related Imaging Abnormality}

Vigabatrin-induced signal changes on MRI were seen in 2/26 cases (7.7\%); both with signal abnormalities in the globus pallidi that disappeared after discontinuation of $\mathrm{Vi}$ gabatrin (Figure 3).

\section{Discussion}

We targeted brain MRI and its role in the etiologic work-up and prognosis of infantile spasm of unknown etiology. Neuroimaging in our study group had substantial influence to further classify infantile spasm in patients when the preliminary clinical evaluation and work-up did not reach a specific diagnosis (16/26 (61.54\%) in our cohort $(\mathrm{p}$-value $=0.0256))$.

In our study, MRI identified brain abnormalities in $73.1 \%(19 / 26)$ of cases versus $26.9 \%$ (7/26) of cases with normal imaging. This is comparable to Saltik et al. [16] who studied a series of 86 patients and found normal MRI in 22 (25.6\%) cases and abnormal MRI in 64 (74.4\%) cases. They found that MRI could solely reveal the underlying cause in $41.8 \%$ of cases which was similar to $30.77 \%(8 / 26)$ of cases in our study. 
2(a): Neurodevelopmental outcome of infantile spasm of unknown etiology

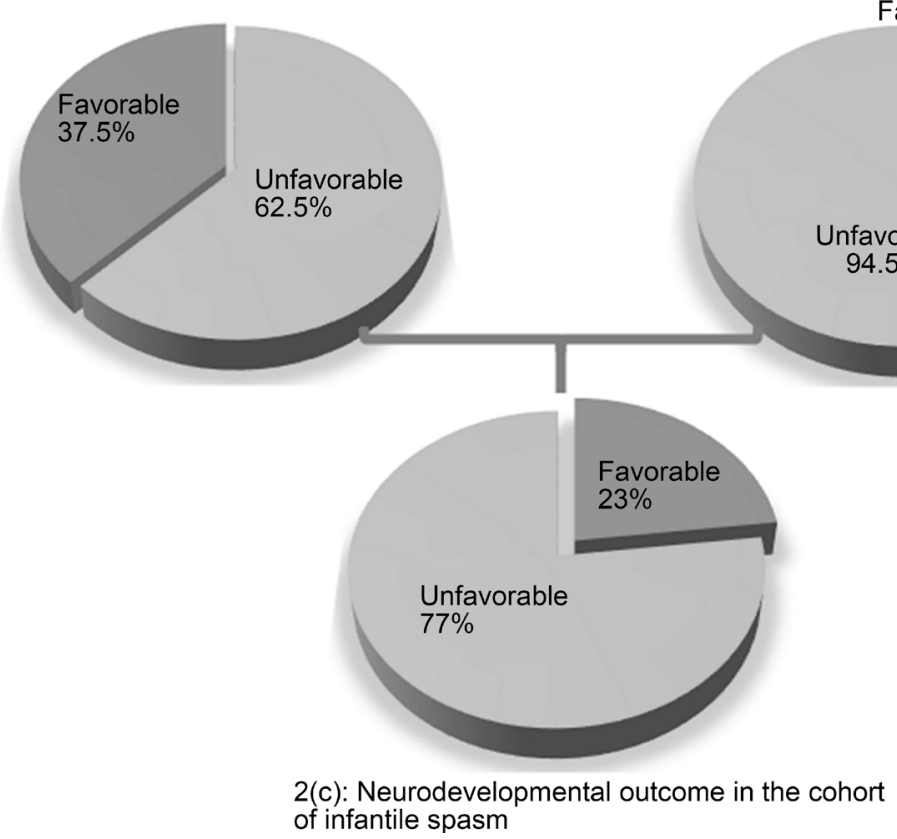

2(b): Neurodevelopmental outcome in structural-metabolic/genetic infantile spasm Favorable $5.5 \%$

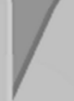

nfavorable $4.5 \%$

Diagram 2. Neurodevelopmental outcome of infantile spasm: (a) unknown etiology; (b) structural-metabolic/genetic; (c) cohort of infantile spasm cases.

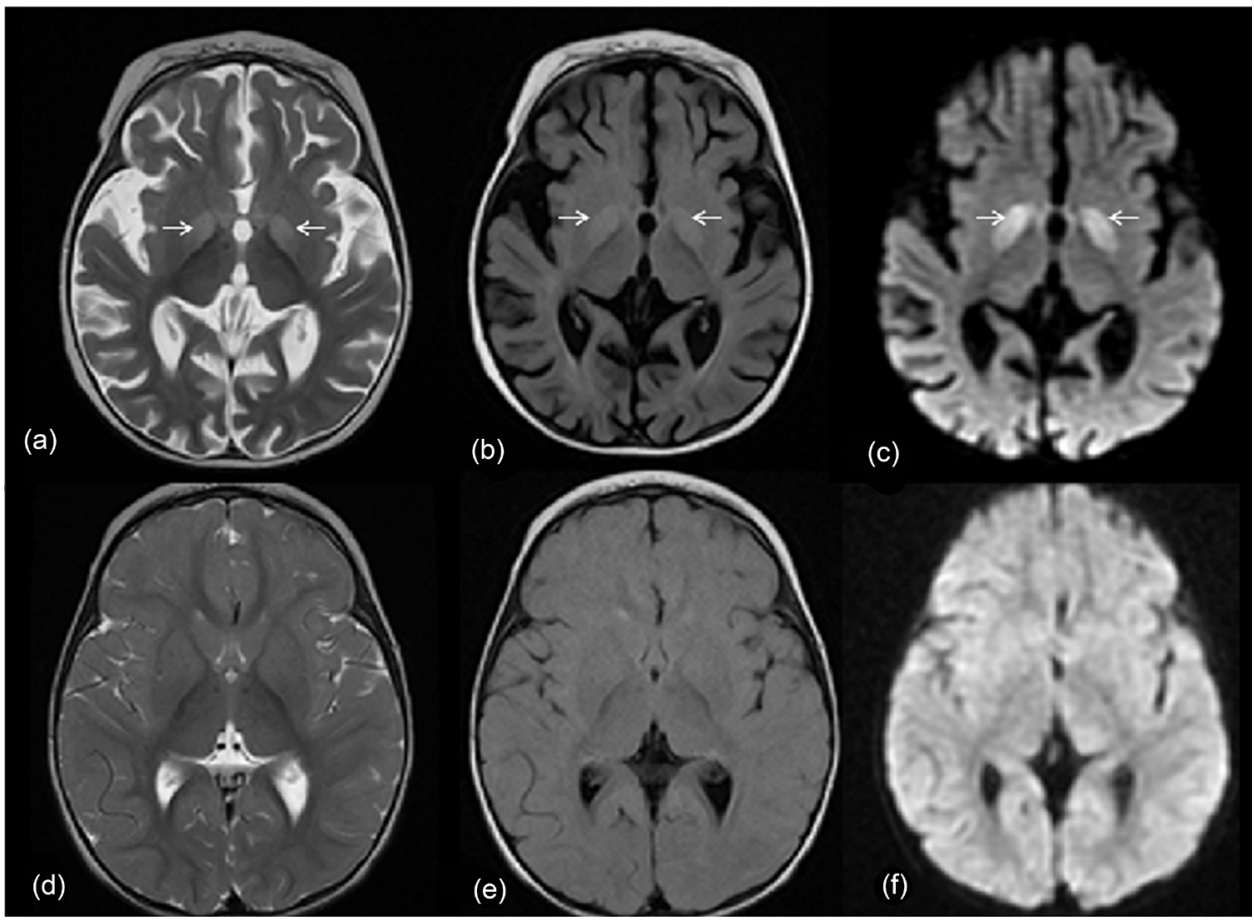

Figure 3. 14-month-old baby girl with trisomy 15 and infantile spasm at 11 months of age (case no. 26). MRI revealed T2W (a) and FLAIR (b) hypersignal intensities in the globus pallidi and restriction in diffusion weighted images (c) (upper row arrows). MRI at the age of 22 months, 6 months after discontinuation of Vigabatrin, reveals resolution of the signal changes (lower row $\mathrm{d}$, e, f). 
The outcome of infantile spasm is generally poor [17]. There is a consensus that when an etiology is not identified in children with infantile spasm, a better prognosis is expected compared to the structural-metabolic type of infantile spasm [17]-[19]. Favorable neurodevelopmental outcome among our patients was achieved in a small number, 6/26 (23.1\%) cases. This proportion was substantially higher among the infantile spasm of unknown etiology group, 5/8 (62.5\%) children in contrast to just 1/18 $(5.55 \%)$ case of favorable outcome in the structural-metabolic/genetic group ( $\mathrm{p}$-value $=$ 0.004). This data is supported by Cohen et al. [18] who reported good neurodevelopmental outcome of infantile spasm of unknown etiology. Our results were comparable to Ducal et al. [20] who reported favorable outcome in $66.67 \%$ of their cryptogenic infantile spasm cases (now classified as infantile spasm of unknown etiology). Our results are also similar and supported by a meta-analysis by Widjaja et al. [17] that reviewed the outcome of 2967 infantile spasm cases and a positive outcome was achieved in $26.4 \%$ of cases $(95 \% \mathrm{CI}=0.197-0.344)$. According to this study, cryptogenic (now classified as unknown etiology) cases had a good outcome in $54.3 \%$ of cases $(95 \% \mathrm{CI}=$ 0.458 - 0.625 ) versus symptomatic (structural-metabolic/genetic) infantile spasm that had a good outcome in $12.5 \%$ of cases $(95 \% \mathrm{CI}=0.09-0.171)$.

The underlying cause of brain abnormalities in our structural-metabolic or genetic group was similar to a larger series by Wheless et al. [21] including: cerebral dysgenesis in $25.4 \%$ of cases, tuberous sclerosis complex (TSC) in $13.7 \%$ of cases, hypoxic-ischemic encephalopathy (HIE) in $8.8 \%$ of cases and chromosomal anomaly in $8.8 \%$ of cases.

Our data indicated that normal imaging was rare in structural-metabolic/genetic infantile spasm and if present, did not carry any predictive value regarding better outcomes compared to structural-metabolic/genetic infantile spasm with abnormal MRI. Being aware of the underlying etiology is possibly the most important criterion to predict the outcome of children with infantile spasm. As established in previous studies [22] [23], infantile spasm of unknown etiology revealed normal MRI or non-specific changes and carried favorable outcomes when compared to structural-metabolic/genetic infantile spasm in our study.

The limitations of this study include the small sample size, heterogeneity of the cases, and the length of time that the cases were followed. It also suffers from lack of specific developmental testing because it is a retrospective study and as a result the neurodevelopmental outcome is evaluated on the data in the patient's clinical chart.

\section{Conclusion}

In summary, i) MRI has a well-established role in identifying the cause of infantile spasm, adding information in $1 / 3$ cases with previously unknown etiology; ii) non-specific findings on MRI follow the same outcome as normal MRI in our cohort; and iii) resolution of spasm is independent of MRI findings, therefore MRI cannot predict spasm medication response.

\section{Declaration of Conflict of Interests}

The authors declared no potential conflicts of interest with respect to the research, au- 
thorship, and/or publication of this article.

\section{Funding}

The authors disclosed no financial support for the research, authorship, and/or publication of this article.

\section{Acknowledgements}

We thank Mrs. Cassandra Kapoor, research administrator at Children's Hospital of Eastern Ontario for the administrative and editorial support.

\section{Author Contributions}

AK contributed in review articles, select patients, data acquisition, interpretation, data analysis, statistics, art works and writing manuscript. MA contributed in review articles and select patients. ES contributed in select cases, clinical interpretation, manuscript writing and manuscript revision. EM supervised the research and contributed in image analysis and interpretation, review articles, critical manuscript revisions and manuscript writing.

\section{Ethical Approval}

The Children's Hospital of Eastern Ontario Research Ethics Board approved this study.

\section{References}

[1] West, W.S. (1841) On a Particular Form of Infantile Convulsions. The Lancet, 1, 724-725. http://dx.doi.org/10.1016/S0140-6736(00)40184-4

[2] Wong, M. and Trevathan, E. (2001) Infantile Spasms. Pediatric Neurology, 24, 89-98. http://dx.doi.org/10.1016/S0887-8994(00)00238-1

[3] Riikonen, R. and Donner, M. (1979) Incidence and Aetiology of Infantile Spasms from 1960 to 1976: A Population Study in Finland. Developmental Medicine \& Child Neurology, 21, 333-343. http://dx.doi.org/10.1111/j.1469-8749.1979.tb01625.x

[4] Paciorkowski, A.R., Thio, L.L. and Dobyns, W.B. (2011) A Genetic and Biologic Classification of Infantile Spasms. Pediatric Neurology, 45, 355-367. http://dx.doi.org/10.1016/j.pediatrneurol.2011.08.010

[5] Trevathan, E., Murphy, C.C. and Yeargin-Allsopp, M. (1999) The Descriptive Epidemiology of Infantile Spasms among Atlanta Children. Epilepsia, 40, 748-751. http://dx.doi.org/10.1111/j.1528-1157.1999.tb00773.x

[6] International League against Epilepsy (ILAE) Definition. http://www.ilae.org/SiteSearch/SearchResults_Google.cfm

[7] Hrachovy, R. (2002) West's Syndrome (Infantile Spasm). Clinical Description and Diagnosis. Advances in Experimental Medicine and Biology, 497, 33-50. http://dx.doi.org/10.1007/978-1-4615-1335-3_5

[8] Cowan, L.D. and Hudson, L.S. (1991) The Epidemiology and Natural History of Infantile Spasms. Journal of Child Neurology, 6, 355-64. http://dx.doi.org/10.1177/088307389100600412

[9] Gibbs, F. and Gibbs, E. (1952) Atlas of Electroencephalography. In: Gibbs, F. and Gibbs, E., 
Eds., Epilepsy, Addision-Wesley, Reading, MA, 2.

[10] Shields, W.D. (2006) Infantile Spasms: Little Seizures, BIG Consequences. Epilepsy Currents, 6, 63-69.

[11] Cerullo, A., Marini, C., Carcangiu, R., Baruzzi, A. and Tinuper, P. (1999) Clinical and Video-Polygraphic Features of Epileptic Spasms in Adults with Cortical Migration Disorder. Epileptic Disorders, 1, 27-33.

[12] Pavone, P., Striano, P., Falsaperla, R., Pavone, L. and Ruggieri, M. (2014) Infantile Spasms Syndrome, West Syndrome and Related Phenotypes: What We Know in 2013. Brain \& Development, 36, 739-751. http://dx.doi.org/10.1016/j.braindev.2013.10.008

[13] Berg, A.T., Berkovic, S.F., Brodie, M.J., Buchhalter, J., Cross, J.H., Van Emde Boas, W., Engel, J., French, J., Glauser, T.A., Mathern, G.W., Moshé, S.L., Nordli, D., Plouin, P. and Scheffer, I.E. (2010) Revised Terminology and Concepts for Organization of Seizures and Epilepsies: Report of the ILAE Commission on Classification and Terminology, 2005-2009. Epilepsia, 51, 676-685.

[14] Fois, A. (2010) Infantile Spasms: Review of the Literature and Personal Experience. Italian Journal of Pediatrics, 36, 15. http://dx.doi.org/10.1186/1824-7288-36-15

[15] Burnham, W.M., Carlen, P.L. and Hwang, P.A. (2002) Intractable Seizure, Diagnosis, Treatment and Prevention. Springer Science + Business Media, New York, 31-50. http://dx.doi.org/10.1007/978-1-4615-1335-3

[16] Saltik, S., Kocer, N. and Dervent, A. (2003) Magnetic Resonance Imaging Findings in Infantile Spasms: Etiologic and Pathophysiologic Aspects. Journal of Child Neurology, 18, 241-246. http://dx.doi.org/10.1177/08830738030180041201

[17] Widjaja, E., Go, C., McCoy, B. and Snead, O.C. (2015) Neurodevelopmental Outcome of Infantile Spasms: A Systematic Review and Meta-Analysis. Epilepsy Research, 109, 155-162. http://dx.doi.org/10.1016/j.eplepsyres.2014.11.012

[18] Cohen-Sadan, S., Kramer, U., Ben-Zeev, B., Lahat, E., Sahar, E., Nevo, Y., Eidlitz, T., Zeharia, A., Kivity, S. and Goldberg-Stern, H. (2009) Multicenter Long-Term Follow-Up of Children with Idio-Pathic West Syndrome: ACTH versus Vigabatrin. European Journal of Neurology, 16, 482-487. http://dx.doi.org/10.1111/j.1468-1331.2008.02498.x

[19] Matsumoto, A., Watanabe, K. and Negoro, T. (1981) Long-Term Prognosis after Infantile Spasms: A Statistical Study of Prognostic Factors in 200 Cases. Developmental Medicine \& Child Neurology, 23, 51-65. http://dx.doi.org/10.1111/j.1469-8749.1981.tb08446.x

[20] Ducal, O., Plouen, P. and Jambaque, I. (1993) Predicting Favourable Outcome in Idiopathic West Syndrome. Epilepsia, 34, 747-756. http://dx.doi.org/10.1111/j.1528-1157.1993.tb00457.x

[21] Wheless, J.W., Carmant, L., Bebin, M., Conry, J.A., Chiron, C., Elterman, R.D., Frost, M., Paolicchi, J.M., Shields, W.D., Thiele, E.A., Zupanc, M.L. and Collins, S.D. (2009) Magnetic Resonance Imaging Abnormalities Associated with Vigabatrin in Patients with Epilepsy. Epilepsia, 50, 195-205. http://dx.doi.org/10.1111/j.1528-1167.2008.01896.x

[22] Saltik, S., Naci Kocer, N. and Aysin Dervent, A. (2002) Informative Value of Magnetic Resonance Imaging and EEG in the Prognosis of Infantile Spasms. Epilepsia, 43, 246-252. http://dx.doi.org/10.1046/j.1528-1157.2002.14001.x

[23] Okumura, A., Watanabe, K., Negoro, T., Aso, K., Natsume, J., Kubota, T., Matsumoto, A., Miura, K., Furune, J., Nomura, K., Hayakawa, F. and Kato, T.E. (1998) Evolutional Changes and Outcome of West Syndrome: Correlation with Magnetic Resonance Imaging Findings. Epilepsia, 43, 46-49. http://dx.doi.org/10.1111/j.1528-1157.1998.tb05150.x 
Submit or recommend next manuscript to SCIRP and we will provide best service for you:

Accepting pre-submission inquiries through Email, Facebook, LinkedIn, Twitter, etc. A wide selection of journals (inclusive of 9 subjects, more than 200 journals)

Providing 24-hour high-quality service

User-friendly online submission system

Fair and swift peer-review system

Efficient typesetting and proofreading procedure

Display of the result of downloads and visits, as well as the number of cited articles

Maximum dissemination of your research work

Submit your manuscript at: http://papersubmission.scirp.org/

Or contactojmi@scirp.org 